\title{
Growth hormone and segmental growth in survivors of head and neck embryonal rhabdomyosarcoma
}

\author{
J R Katz, P Bareille, G Levitt, R Stanhope
}

\begin{abstract}
Aims-To assess the impact of treatment for embryonal rhabdomyosarcoma on spinal growth and limb length and examine the response of these parameters to growth hormone (GH) treatment.

Methods-We conducted a retrospective case note review of 17 survivors of head and neck rhabdomyosarcoma followed up at a single institution. All children had been treated with chemotherapy and local radiotherapy. Growth velocity, height, sitting height, and subischial limb length SDS scores were analysed.

Results-Growth failure secondary to isolated GH deficiency (GHD) developed in 7/17 patients. GHD occurred at a median (range) of 3.4 (1.3-9.9) years after radiotherapy tumour doses of 46 (40-50) Gy. Growth velocity, height, and subischial limb length SDS were significantly reduced in the GHD group and improved with GH therapy.

Conclusions-GH treatment resulted in a significant improvement in sitting height SDS. We discuss the unexpected improvement in spinal growth in survivors with GHD.

(Arch Dis Child 2001;84:436-439)
\end{abstract}

Keywords: rhabdomyosarcoma; pituitary function; growth hormone

In 1966 , the first case of pituitary dwarfism secondary to radiotherapy was described. ${ }^{1}$ Growth hormone deficiency (GHD) has commonly been reported following treatment of primary brain tumours ${ }^{2-5}$ or extracranial tumours when the dose to the hypothalamopituitary axis (HPA) is in excess of $27 \mathrm{~Gy} .{ }^{6}$ The evidence suggests that GHD is usually caused by radiation damage to the hypothalamus. ${ }^{7}$ Higher radiation doses, in the region of $50 \mathrm{~Gy}$, may cause multiple anterior pituitary hormone deficiencies. ${ }^{8}$ Reduced sitting height is an established consequence of spinal irradiation. ${ }^{4}$ However, it is more difficult to define the independent effects of individual cytotoxic drugs on growth, ${ }^{6}$ as they are usually given in multimodal treatment protocols in the treatment of head and neck tumours.

Embryonal rhabdomyosarcoma (RMS) is the most common soft tissue sarcoma of the head and neck in children, although it accounts for less than $2 \%$ of childhood cancers. ${ }^{9}$ Treatment regimens consisting of surgery, local radiotherapy, and multiple agent chemo- therapy have improved the prognosis of RMS of the head and neck. ${ }^{10}$ Although average survival across all age groups is $35 \%$ at 10 years, children fare significantly better than adults. ${ }^{11}$ The recent Intergroup RMS Studies (IRS) reported a 53\% five year survival in children. ${ }^{12}$

In 1976, the first case of pituitary dwarfism following radiotherapy for head and neck RMS was reported. ${ }^{13}$ From 1964 to 1984 , eight cases of nasopharyngeal RMS were diagnosed in the Toronto Hospital for Sick Children, of whom five survived more than two years..$^{14}$ Of these, one developed panhypopituitarism, but the radiotherapy dose given was not stated. The Philadelphia experience from 1972 to 1981 describes 15 cases of head and neck RMS, of whom three developed GHD four to 10 years after radiotherapy. ${ }^{9}$ However, none of the five orbital RMS patients in this survey developed GHD. The IRS reported on late sequelae of treatment of non-orbital RMS; of 190 children, $92(48 \%)$ had failed to maintain their growth velocity and $36(19 \%)$ were diagnosed with GHD. ${ }^{12}$ In a recent UK study, seven of 16 survivors of RMS (including 12 orbital RMS cases) were treated with $\mathrm{GH}$ and all showed responses to therapy with improved height SDS scores. ${ }^{15}$

While there is a growing literature on failure of linear growth in survivors of head and neck RMS treated with chemotherapy and radiotherapy, there are no data examining segmental growth in RMS survivors. We conducted this survey to assess the growth and endocrine consequences of treatment in a group of survivors of head and neck RMS. In particular we measured spinal and subischial limb length in RMS survivors and assessed the response of segmental growth to $\mathrm{GH}$ therapy in those with GHD.

\section{Patients and methods}

We analysed data from the 17 patients diagnosed with head and neck RMS at this institution between 1986 and 1997, who had survived at least two years event free after completion of chemotherapy and radiotherapy (follow up interval at least two years). Table 1 summarises characteristics of the subjects. Twelve of these children were referred to a joint paediatric oncology/endocrinology clinic for assessment of growth. Of the remaining five, four had normal linear growth and were followed up in an oncology clinic, and one (case 15) died six years after treatment of RMS after developing a brain stem glioma. 
Table 1 Characteristics of the subjects

\begin{tabular}{|c|c|c|c|c|c|c|c|c|c|c|}
\hline No. & Sex & Tumour site & $\begin{array}{l}\text { Age at } \\
\text { diagnosis (y) }\end{array}$ & $\begin{array}{l}\text { Age at follow } \\
u p(y)\end{array}$ & $\begin{array}{l}\text { Follow up } \\
\text { interval (y) }\end{array}$ & $\begin{array}{l}\text { Chemotherapy } \\
\text { protocol }\end{array}$ & $\begin{array}{l}\text { Dexa } \\
\text { given }\end{array}$ & $\begin{array}{l}\text { Tumour } \\
\text { radiotherapy } \\
\text { dose }(G y)\end{array}$ & $\begin{array}{l}\text { Pituitary } \\
\text { radiotherapy } \\
\text { dose }(G y)\end{array}$ & $\begin{array}{l}\text { GHD (follow } \\
\text { up interval at } \\
\text { GHD } \\
\text { diagnosis) }\end{array}$ \\
\hline 1 & $\mathrm{M}$ & Orbit & 0.3 & 12.9 & 12.1 & $\mathrm{~V}, \mathrm{~A}, \mathrm{C}, \mathrm{D}, \mathrm{E}$ & $\mathrm{N}$ & 40 & ? & $\mathrm{Y}(9.9)$ \\
\hline 2 & $\mathrm{M}$ & Orbit & 8.8 & 11.8 & 2.4 & SIOP MMT'95-A & $\mathrm{Y}$ & 45 & 27.5 & $\mathrm{~N}$ \\
\hline 3 & M & Orbit/PM & 6.1 & 14.5 & 8.1 & SIOP MMT'89-D & $\mathrm{N}$ & 50 & ? & $\mathrm{Y}(3.2)$ \\
\hline 4 & $\mathrm{M}$ & Buccal & 2.6 & 10.9 & 7.8 & SIOP MMT'89-E & $\mathrm{N}$ & 45 & ? & $\mathrm{N}$ \\
\hline 5 & $\mathrm{~F}$ & Parotid & 6.3 & 12.8 & 6.1 & SIOP MMT'89-D & $\mathrm{Y}$ & 46 & 37.5 & $\mathrm{~N}$ \\
\hline 6 & $\mathrm{~F}$ & Ear & 1.8 & 8.0 & 5.8 & SIOP MMT'89-D & $\mathrm{N}$ & 47 & 27.5 & $\mathrm{~N}$ \\
\hline 7 & M & Ear & 3.6 & 13.2 & 9.3 & V, A, C, Ad & $\mathrm{N}$ & 43 & $<2$ & $\mathrm{~N}$ \\
\hline 8 & $\mathrm{M}$ & Ear & 5.2 & 13.4 & 7.9 & SIOP MMT'89-D & $\mathrm{N}$ & 45 & $<22.5$ & $\mathrm{Y}(3.3)$ \\
\hline 9 & M & Nasopharynx & 3.6 & 9.6 & 5.6 & SIOP MMT'89-E & $\mathrm{Y}$ & 50 & ? & $\mathrm{Y}(3.4)$ \\
\hline 10 & $\mathrm{~F}$ & Nasopharynx & 9.1 & 13.3 & 3.9 & SIOP MMT'89-D & $\mathrm{Y}$ & 50 & 27.5 & $\mathrm{Y}(1.3)$ \\
\hline 11 & M & Nasopharynx & 4.0 & 7.4 & 2.6 & SIOP MMT95-B & $\mathrm{Y}$ & 50 & 36 & $\mathrm{~N}$ \\
\hline 12 & $\mathrm{~F}$ & Ear & 4.9 & 7.9 & 2.3 & SIOP MMT'95-B & $\mathrm{Y}$ & 50 & 30.5 & $\mathrm{~N}$ \\
\hline 13 & M & Parotid & 8.5 & 13.8 & 4.5 & SIOP MMT'89-D & $\mathrm{Y}$ & 50 & $<25$ & $\mathrm{~N}$ \\
\hline 14 & $\mathrm{M}$ & Ear & 6.4 & 14.1 & 7.4 & SIOP MMT'89-D & $\mathrm{N}$ & 50 & 48 & $\mathrm{Y}(2.8)$ \\
\hline 15 & $\mathrm{~F}$ & Palatal & 2.9 & 10.3 & 6.4 & SIOP MMT'89-D & $\mathrm{N}$ & 45 & $<2$ & $\mathrm{~N}$ \\
\hline 16 & $\mathrm{M}$ & Nasopharynx & 6.2 & 14.5 & 7.9 & SIOP MMT'89-D & $\mathrm{N}$ & 45 & ? & $\mathrm{Y}(2.7)$ \\
\hline 17 & M & Nasopharynx & 1.8 & 4.6 & 2.3 & SIOP MMT'95-B & $\mathrm{Y}$ & 45 & 27.5 & $\mathrm{~N}$ \\
\hline
\end{tabular}

Dexa, dexamethasone; PM, parameningeal; V, vincristine; A, actinomycin; Ad, Adriamycin; C, cyclophosphamide; D, doxorubicin; E, etoposide; I, ifosfamide; SIOP, International Society of Paediatric Oncology; MMT, malignant mesenchymal tumor; Y, Yes; N, No; ?, unknown pituitary radiation dose.

All 17 patients had biopsies, but only three had surgical debulking (patients 5, 7, 8). Fifteen patients were treated according to International Society of Paediatric Oncology malignant mesenchymal tumour (SIOP MMT) 1989 or 1995 protocols. ${ }^{16-18}$ The principal chemotherapy agents involved were vincristine, actinomycin, and ifosfamide. Eight patients were given dexamethasone (see table 1) with ifosfamide $0.1-0.4 \mathrm{mg} / \mathrm{kg}$, on six occasions during their chemotherapy treatment. All patients were treated with radiotherapy via $6 \mathrm{MV}$ portals in 21-27 fractions over four to five weeks. Radiotherapy planning films were available in 12 patients. Table 1 shows chemotherapy protocols for each patient and estimated pituitary radiation doses (in 12 patients).

Case notes of the 17 children were reviewed retrospectively. The children's height had been recorded every six months after treatment for RMS. In addition, sitting height and subischial limb length were recorded at intervals. Glucagon tests were carried out in those children who developed growth failure. This test was combined with a thyrotrophin releasing hormone (TRH) test and (in the presence of delayed puberty) with a luteinising hormone releasing hormone (LHRH) test. The intravenous doses used were glucagon $100 \mu \mathrm{g} / \mathrm{kg}$, TRH $7 \mu \mathrm{g} / \mathrm{kg}$ (maximum $200 \mu \mathrm{g}$ ), and LHRH $25 \mu \mathrm{g} / \mathrm{m}^{2}$. GHD was diagnosed in patients with a peak $\mathrm{GH}$ of less than $20 \mathrm{mU} / 1$ after glucagon stimulation.

SDS scores for growth velocity, height, sitting height, and subischial limb length were calculated for each clinic visit. For the non-GHD group, we analysed the SDS scores relating to the most recent outpatient visit, the growth velocity SDS being derived from the

Table 2 Comparative data of non-GHD and GHD groups, prior to GH therapy

\begin{tabular}{lll}
\hline & $G H D(n=7)$ & Non-GHD (n=10) \\
\hline Age at most recent visit (y) & $13.4^{\star}(12.9$ to 14.5$)$ & $10.3^{\star}(7.4$ to 12.3$)$ \\
Follow up interval (y) & $7.9(5.6$ to 8.1$)$ & $5.8(2.4$ to 7.1$)$ \\
Growth velocity SDS & $-1.63^{\star}(-3.12$ to -0.55$)$ & $1.75^{\star}(0.01$ to 2.78$)$ \\
Height SDS & $-1.0^{\star}(-1.40$ to -0.60$)$ & $0.30^{\star}(-0.43$ to 0.70$)$ \\
Sitting height SDS & $-1.19(-1.5$ to -0.80$)$ & $-0.51(-1.06$ to 1.00$)$ \\
Subischial limb length SDS & $-0.37^{\star}(-0.90$ to -0.19$)$ & $0.98^{\star}(-0.19$ to 1.92$)$ \\
\hline
\end{tabular}

All values expressed as median (interquartile range).

${ }^{\star} \mathrm{p}<0.05$ for Mann-Whitney test for differences between GHD and non-GHD groups. rate of change in height between the penultimate and the most recent outpatient visit. For the GHD group, we analysed the SDS scores immediately prior to starting $\mathrm{GH}$ treatment (pre-GH) and one to four years after commencing GH therapy. For analysis of differences between pre-GH GH deficient and nonGHD groups, the Mann-Whitney test was applied. For comparison of growth parameters in the GHD group, before and after $\mathrm{GH}$ therapy, the Wilcoxon test was used.

\section{Results}

Seven of 17 children developed growth failure secondary to GHD, with a GH peak after glucagon of less than $20 \mathrm{mU} / 1$. The diagnosis of GHD was established a median of 3.2 (range 1.3-9.9) years after radiotherapy doses of a median of 46 (range 40-50) Gy. Six of the seven GHD cases were diagnosed within four years of completing radiotherapy (see table 1). The GHD group was older than the non-GHD group and there was a non-significant trend towards longer follow up in the GHD group (see table 2). There was no relation between age at diagnosis or total radiotherapy dose and the development of GHD in our cohort. Pituitary radiation dose estimates were available in three of seven GHD patients (see table 1). Two of these had received pituitary doses in excess of $27 \mathrm{~Gy}$ and one received less than $22.5 \mathrm{~Gy}$. In three of the five cases where a quantitative dose estimate was not available, it was established from the site of the tumour that the pituitary radiation dose was significant in cases 3 and 9 and minimal in case 4 .

Table 2 summarises the growth data of the GHD and non-GHD groups. The non-GHD group had normal linear growth as reflected in their growth velocity SDS scores. There were significant reductions in growth velocity, height, and subischial limb length SDS in the GHD group compared with the non-GHD group. In both GHD and non-GHD groups sitting height SDS scores were low, with a nonsignificant trend to lower scores in the GHD group. There was no relation between height, sitting height, or subischial limb length SDS scores and either the chemotherapy protocol 

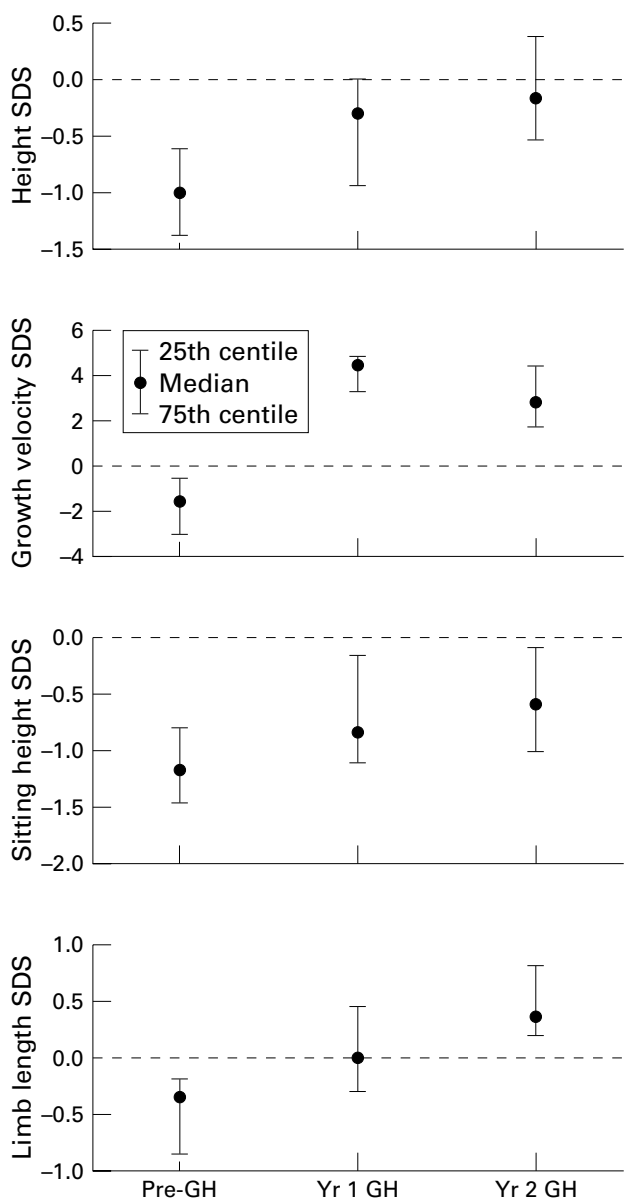

Figure 1 Growth data (SDS scores-median, quartiles) of GHD group $(n=7)$ immediately before, and one and two years after commencement of $\mathrm{GH}$ treatment.

chosen or the administration of dexamethasone. All seven GHD patients had received GH therapy for at least two years at the time of this review, while three had been treated for four years. Growth velocity, height, sitting height, and subischial limb length SDS all improved significantly at one and two years after initiation of $\mathrm{GH}$ therapy $\left(20 \mathrm{IU} / \mathrm{m}^{2} /\right.$ week; see fig 1) compared with pre-GH baseline scores. After treatment for 3 and 4 years, all subjects showed sustained improvements in growth and segmental growth, but there were insufficient numbers at these stages to validate this observation statistically.

One of these children had treated congenital hypothyroidism, but there was no evidence of pituitary hormone deficiencies other than GHD resulting from treatment of RMS. Only one patient (case 3) had delayed puberty. $\mathrm{He}$ had a flat response to LHRH prior to a six month course of testosterone $(50 \mathrm{mg}$ intramuscularly monthly). His testicular volume increased to $10 \mathrm{ml}$ on testosterone therapy; clinically, this is more likely to be constitutional delayed puberty than hypogonadotrophic hypogonadism.

\section{Discussion}

Growth hormone deficiency occurred in seven of 17 survivors of RMS. The interval between radiotherapy and the onset of GHD is highly variable and this highlights the need for continued monitoring for GHD in RMS survivors until final height is reached. The reduction in growth velocity, height, and subischial limb length in the GHD group prior to treatment and the subsequent increase in these parameters with GH therapy was expected. Sitting height SDS was reduced in GHD and non-GHD subjects (see table 2 ) without a significant difference between the two groups. The improvement in upper segment growth in the first two years of growth hormone therapy was unexpected.

While some degree of caution is required in interpreting the growth data of such a small group of patients, the reduction in sitting height SDS in the non-GHD and GHD survivors of RMS needs some explanation. None of these children had received spinal irradiation. The independent effects of radiotherapy, chemotherapy, and underlying disease on growth are difficult to differentiate. Shalet and colleagues ${ }^{6}$ have suggested that chemotherapy and malignancy as well as radiotherapy may cause short stature in the absence of GHD. Reduced height SDS has been reported in children given chemotherapy without cranial irradiation for treatment of primary brain tumours. ${ }^{5}$ It has been appreciated that children treated for acute lymhoblastic leukaemia with combination chemotherapy and cranial irradia$\operatorname{tion}^{19}$ have relatively short upper to lower body segment ratios. In addition, total body irradiation $^{20}$ has a greater effect on growth of the spine than of the lower limbs. These observations may be explained by the large number of epiphyseal growth plates in the vertebral column compared to those of the lower limb. In vitro studies have shown a direct effect of corticosteroids and chemotherapeutic agents on rat chondrocyte proliferation. ${ }^{21}$ It is unlikely that the small doses of dexamethasone given to eight of the 17 patients in our study led to reduced spinal growth and this is borne out by the analysis. However, the impaired spinal growth in the non-GHD and GHD patients in our study may be explained by a direct effect of chemotherapy on vertebral growth plates.

Most studies of GHD children show significant improvements in limb length, rather than spinal growth, with $\mathrm{GH}$ therapy. In our $\mathrm{GH}$ treated group (fig 1), we showed significant improvements in spinal growth as well as limb length. This finding is more difficult to explain, but one could propose that GH therapy reversed the toxic effects of chemotherapy on epiphyseal growth plates. However, one must be cautious in extrapolating from the data, given the limited numbers studied. A larger study would be needed to confirm this finding.

Cranial irradiation of the hypothalamus remains the likely cause of GHD in the seven affected children. Although an earlier study ${ }^{9}$ reported no cases of GHD in five survivors of orbital RMS six years after treatment, we have shown GHD in two of three cases of orbital RMS, three and 10 years after radiotherapy. This concurs with another recent study, which found seven of 12 orbital RMS survivors had biochemical evidence of GHD, four of whom 
required treatment with GH. ${ }^{15}$ Our study confirms that children who have received radiotherapy for treatment of RMS of the ear, orbit, or nasopharynx are clearly at risk of GHD, particularly when the hypothalamopituitary axis is within the radiation field.

The risk of GHD and multiple pituitary hormone deficiencies (MPHD) experienced in adulthood has been shown to be closely related to the dose of cranial irradiation used in the treatment of childhood brain tumours. ${ }^{8}$ Shalet and colleagues ${ }^{22}$ described 20 such adults who had received 29-50 Gy of cranial irradiation some 8-32 years previously. Of these, nine developed GHD, but none developed MPHD. However doses of $50-83 \mathrm{~Gy}^{23}$ have been associated with MPHD. In these patients, the pituitary dose was equal to the whole brain dose, but this was not the case in our RMS patients, where the pituitary received a proportion of the total dose. Given the fact that none of the pituitary doses exceeded $48 \mathrm{~Gy}$, there is only a low probability that any of our patients will develop MPHD.

While it is accepted that the risk of GHD is directly related to the dose of radiotherapy the hypothalamopituitary axis receives, ${ }^{12}$ this is not always borne out by the data in published studies. ${ }^{15}$ In the IRS, pituitary doses were reported in GHD patients, all of whom received in excess of $35 \mathrm{~Gy}$ to the pituitary gland. ${ }^{12}$ However, growth assessment of nonGHD patients was not stratified according to pituitary doses, as these were not measured in non-GHD children. Another recent study ${ }^{15}$ reports pituitary doses in all subjects, but interestingly, one of their GHD subjects had received a pituitary dose of $24 \mathrm{~Gy}$, which was the lowest pituitary dose in their cohort. Similarly, one of our GHD patients (case 8) received a pituitary dose less than $22.5 \mathrm{~Gy}$, not normally associated with GHD. Notwithstanding the fact that planning films were not available in five subjects in our cohort, there was considerable overlap between non-GHD and GHD subjects in terms of pituitary radiation exposure. Thus, pituitary dose estimations are a useful guide, but do not universally predict the onset of GHD.

The reduction in sitting height in non-GHD survivors of RMS adds clinical support to in vitro data ${ }^{21}$ suggesting a direct effect of chemotherapy on the vertebral growth plates. In GHD survivors of RMS, both upper and lower segment growth respond to $\mathrm{GH}$ therapy. We discovered GHD in seven of 17 survivors of head and neck RMS. Given the lag effect of radiotherapy, the remaining RMS survivors will need continued monitoring for the development of growth failure.
1 Tan BC, Kunaratnam N. Hypopituitary dwarfism following radiotherapy for nasopharyngeal carcinoma. Clin Radiol 1966;17:302-4.

2 Livesey EA, Hindmarsh PC, Brook CG, et al. Endocrine disorders following treatment of childhood brain tumours. Br f Cancer 1990;61:622-5.

3 Abayomi OK, Sadeghi Nejad A. The incidence of late endocrine dysfunction following irradiation for childhood medulloblastoma. Int $\mathcal{F}$ Radiat Oncol Biol Phys 1986;12: 945-8.

4 Brown IH, Lee TJ, Eden OB, et al. Growth and endocrine function after treatment for medulloblastoma. Arch Dis Child 1983;58:722-7.

5 Ilveskoski I, Saarinen UM, Wikland T, et al. Growth impairment and growth hormone therapy in children treated for malignant brain tumours. Eur F Pediatr 1997;156:764-9.

6 Shalet SM, Beardwell CG, Aarons BM, et al. Growth impairment in children treated for brain tumours. Arch Dis Child 1978;53:491-4.

7 Littley MD, Shalet SM, Beardwell CG. Radiation and hypothalamic-pituitary function. Baillieres Clin Endocrinol Metab 1990;4:147-75.

8 Shalet SM. Growth and hormonal status of children treated for brain tumours. Childs Brain 1982;9(3-4):284-93.

9 Fromm M, Littman P, Raney RB, et al. Late effects after treatment of twenty children with soft tissue sarcomas of the head and neck. Experience at a single institution with a review of the literature. Cancer 1986;57:2070-6.

10 Pawel BR, Hamoudi AB, Asmar L, et al. Undifferentiated sarcomas of children: pathology and clinical behavior-an Intergroup Rhabdomyosarcoma study. Med Pediatr Oncol 1997;29:170-80.

11 La Quaglia MP, Heller G, Ghavimi F, et al. The effect of age at diagnosis on outcome in rhabdomyosarcoma. Cancer 1994;73:109-17.

12 Raney RB, Asmar L, Vassilopoulou-Sellin R, et al. Late complications of therapy in 213 children with localized, nonorbital soft-tissue sarcoma of the head and neck: a descriptive report from the Intergoup Rhabdomyosarcoma Sescriptive report from the Intergoup Rhabdomyosarcoma Studi.

13 Fuks Z, Glatstein E, Marsa GW, et al. Long-term effects of external radiation on the pituitary and thyroid glands. Cancer 1976;37(suppl 2):1152-61.

14 Fearon B, Forte V, Brama I. Malignant nasopharyngeal tumors in children. Laryngoscope 1990;100:470-2.

15 Goddard AG, Harris SJ, Plowman PN, et al. Growth hormone deficiency following radiotherapy for orbital and parameningeal sarcomas. Pediatr Hematol Oncol 1999;16: paramen.

16 Otten J, Flamant F, Rodary C, et al. Treatment of rhabdomyosarcoma and other malignant mesenchymal tumours of childhood with ifosfamide + vincristine + dactinomycin (IVA) as front-line therapy (a SIOP study). Cancer Chemother Pharmacol 1989;24(suppl 1):S30.

17 Martelli H, Oberlin O, Rey A, et al. Conservative treatment for girls with nonmetastatic rhabdomyosarcoma of the genital tract: a report from the Study Committee of the International Society of Pediatric Oncology. 7 Clin Oncol 1999;17:2117-22.

18 Sommelet D, Pinkerton R, Brunat Mentigny M, et al. Standards, options and recommendations (SOR) for clinical care of rhabdomyosarcoma (RMS) and other soft tissue sarcoma in children. Federation of the French Cancer Centers. French Society of Pediatric Oncology (published erratum appears in Bull Cancer 1999;86:232). Bull Cancer 1998;85:1015-42.

19 Davies HA, Didcock E, Didi M, et al. Disproportionate short stature after cranial irradiation and combination chemotherapy for leukaemia. Arch Dis Child 1994;70: $472-5$.

20 Papadimitriou A, Uruena M, Hamill G, et al. Growth hormone treatment of growth failure secondary to total body irradiation and bone marrow transplantation. Arch Dis Child 1991;66:689-92.

21 Robson H, Anderson E, Eden OB, et al. Chemotherapeutic agents used in the treatment of childhood malignancies have direct effects on growth plate chondrocyte proliferation. F Endocrinol 1998;157:225-35.

22 Shalet SM, Beardwell CG, MacFarlane IA, et al. Endocrine morbidity in adults treated with cerebral irradiation for brain tumours during childhood. Acta Endocrinol (Copenh) 1977;84:673-80.

23 Samaan NA, Bakdash MM, Caderao JB, et al. Hypopituitarism after external irradiation. Evidence for both hypothalamic and pituitary origin. Ann Intern Med 1975;83:771-7. 